INTERNATIONAL DESIGN CONFERENCE - DESIGN 2018

https://doi.org/10.21278/idc.2018.0530

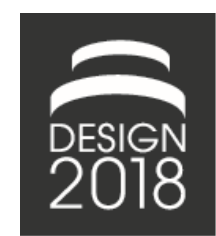

\title{
MANUFACTURING TECHNOLOGY-BASED APPROACH TO TEACHING ENGINEERING DRAWING
}

\author{
D. Žeželj and D. Miler
}

\begin{abstract}
Engineering drawing is of vital importance to the designer since it enables sharing the design solution with the rest of the team. Even though recommendations for the dimension arrangement are provided in the national standards, general solutions are not offered. For this reason, dimensioning strategy in teaching technical drawing is required. In this article, the authors studied the manufacturing technologybased teaching approach by analysing the learning outcomes and the feedback from the students. During the time span of five years, 814 students responded to the student questionnaire.
\end{abstract}

Keywords: design education, engineering design, cognitive capabilities, technical drawing, dimensioning

\section{Introduction}

During the everyday communication, engineers use drawings to express their thoughts and exchange ideas within the team, or when generating concepts in brainstorming. Engineers have a wide array of design tools at their disposal, among them computer-aided design (CAD). Today, designing without the use of computer-aided design and drafting (CADD) is rare because it has numerous advantages; its use for avoiding tedious tasks such as manual detailing reduces the design process length. However, to be able to properly use the software, engineering students have to master the basics of technical drawing in the first place.

To find requirements for CAD tools, Ullman et al. (1990) studied the importance of technical drawing in the design process. The authors concluded that many drawing actions are carried out not only to document the results but also to help the designer design. Robb et al. (2009) recognised sketching as a core requirement for mechanical engineers and suggested to adopt the strategy for developing sketching skills implemented at the Imperial College London. The approach included the hands-on involvement, the sketching training, and the recognition of the value of observation for the drawing skill development. Baronio et al. (2016) observed that students have difficulties in using the manufacturing approach to dimensioning. The self-learning tool used at the Universities of Brescia and Udine was presented; before the dimensioning task, a simple video clip of a part being machined was shown to the students. The authors reported an $8.8 \%$ increase in the average grade.

At the Faculty of Mechanical Engineering and Naval Architecture (FMENA), University of Zagreb, Croatia, engineering drawing is taught to mechanical, naval, and aerospace engineering students during the first semester. Students attend two hours of lectures and two hours of design exercises per week. Among other things, students are taught to dimension the frequently used design elements (flanges, shafts, nuts) to provide a basis for understanding the design elements and CAD, which are vital for the mechanical engineering students. 
When teaching dimensioning in engineering drawing, students are taught to approach the problem from a manufacturing technology (MT) viewpoint; this means that the order of dimensions drawn should follow the order of manufacturing operations. This approach encourages the students to pay attention to the manufacturing feasibility of a part in the later years of their studies. The problem with the first-year students is that they have different backgrounds and often lack the basic knowledge about manufacturing processes; this problem requires special care in the teaching of a course in engineering drawing.

\subsection{Importance of the prior secondary education}

Generally, after primary education, students opt for general secondary schools which enable easier access to tertiary education. According to the Eurostat (2017a), in the period 2010-2016, the percentage of the population that attained the upper secondary and the post-secondary non-tertiary education rose from $46.2 \%$ to $46.4 \%$. At the same time, the percentage of the population that attained the tertiary education rose from $16.9 \%$ to $19.8 \%$. The data refer to EU28, age class $15-29$. At the secondary education level, the percentage of population that attained the vocational secondary education fell from $27.8 \%$ to $27.3 \%$ (Eurostat, $2017 \mathrm{~b}$ ). The percentage of population with the general secondary education remained almost unchanged, i.e. it increased by $0.1 \%$. The programme orientation data refer to EU28, the age class 15-34 and the period 2014-2016 (there are no data available for the period 2010-2013). For countries with a higher GDP, the decline in the vocational education was even more serious, e.g. in Germany from $37.4 \%$ to $35.7 \%$, in Sweden from $23.7 \%$ to $21.2 \%$, in Norway from $17.4 \%$ to $12.9 \%$, and in Switzerland from 31.3\% to 29.6\%. The UK Department of Education study showed that the main cause of that was the higher adaptability provided by general education programmes, which resulted in better employment opportunities later in life (Hampf and Woessmann, 2016).

In the period up to 2010, applicants for graduate study at the universities in Croatia were required to pass an entrance exam; this was replaced with the state graduation exam in 2010. Thus, graduate admission is available to applicants who have finished either the vocational or the general (grammar schools) secondary education. For this reason, applicants display different levels of prior knowledge of mathematics, physics, engineering drawing, and manufacturing processes. Students who have finished vocational technical school often demonstrate limited knowledge of mathematics and physics on the one hand, but have a better understanding of manufacturing processes on the other. This enables them to grasp the concept of manufacturing technology-based (MTB) approach to engineering drawing faster. In addition, these students have enhanced spatial visualisation ability due to the spatial activities performed during their secondary education, as stated by Alias et al. (2002).

As shown in Figure 1, due to a rise in demand, the total number of mechanical engineering (ME) students enrolled at FMENA rose from 330 in 2010 to 435 in 2017. However, the number of applicants with vocational secondary education declined from 109 to 69 , while, at the same time, the number of applicants with general secondary education rose from 210 to 358 . The remaining students came from artistic and craft schools, or the school type was not determined.

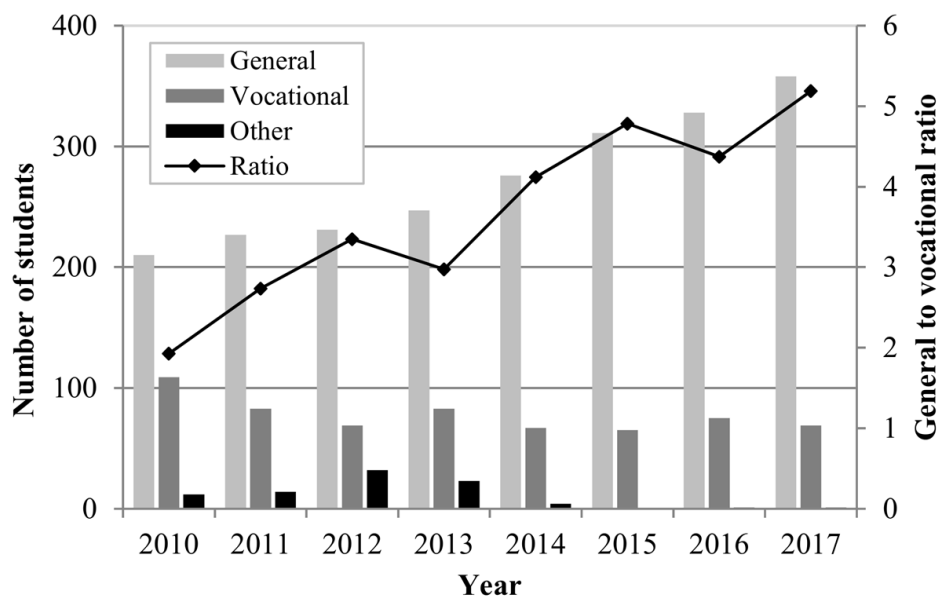

Figure 1. The first-year ME students separated by secondary education type 
Due to the rising number of applicants with general secondary education, we observed the effects of secondary education type on the results achieved in the Engineering Drawing course. Furthermore, the applicability of the current curriculum was considered since the MTB approach to engineering drawing is harder to master for students with no prior knowledge of manufacturing processes. This approach has been adopted because it is expected that the students will benefit from it later in their studies. In this article, we observe the grades attained in the Engineering Drawing course and the feedback obtained from student questionnaires. Our goal was to offer an insight into the course of engineering drawing.

\subsection{Problem formulation}

The main problem when teaching the first-year students the MTB approach to engineering drawing is the lack of prior knowledge. In this article, the authors present the method used at FMENA, along with the results and feedback provided by the students who attended the course in the period 2010-2017.

Even though the MTB approach offers many benefits, there are obstacles to overcome. The total number of students attending the Engineering Drawing course at the moment is 510; 435 students of mechanical engineering, 45 of naval architecture, and 30 of aerospace engineering. Furthermore, from 2010 to 2017, on average, 32 students per academic year had to retake the course, with a maximum of 39 students in 2012/2013 and a minimum of 23 in 2015/2016. The increasing number of students further increases the workload; more exams are to be corrected and more lecture groups are required. Since the examined knowledge of the freehand sketching is rather specific, it is not possible to automatize the exam grading process, which means that each exam has to be graded individually, taking between 7 and 10 minutes. Engagement of additional staff probably with different criteria in grading may cause problems and often leads to students' disappointment with the exam results since students share their experiences.

\section{Approaches to teaching engineering drawing}

From the manufacturing and the final inspection point of view, dimensional and geometrical dimensioning of the part is of crucial importance. Engineering drawing can be observed as a set of dimensional and geometrical instructions to the manufacturer so that the part can fulfil its purpose as decided by the designer. Through the drawing, the designer communicates his design solution to the rest of the team. It is expected that the designer has, at least, a basic knowledge of manufacturing technologies because the solution should be oriented towards the available manufacturing process.

The international standard covering the indication of dimensions and dimensional tolerances (ISO, 2004) does not explain why dimensions should be arranged in one way or another, but only offers ways and examples how to do it properly. Based on the same standard (ISO, 2004), dimension lines are arranged as parallel, chain, and running dimensioning, or in combination. The running dimensioning can be observed as a variant of the parallel dimensioning; thus, the focus will be laid only on the parallel and the chain dimensioning and their combination (Figure 2).

a)

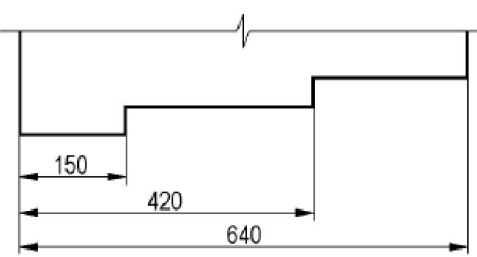

b)

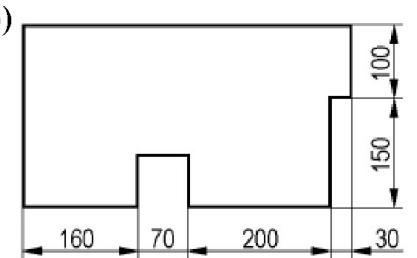

c)

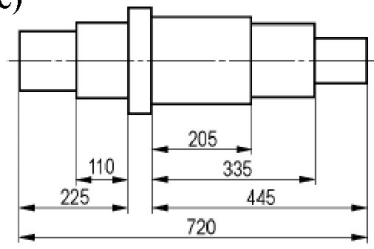

Figure 2. Arrangements of dimension lines: a) parallel, b) chain, and c) combined parallel and chain

The standard does not offer dimensioning solutions; it only gives a tool for any user to do that uniformly. It is up to the user to decide which of the arrangements or combinations of arrangements should be applied to a certain situation. At this point, the tool is known, but there is no strategy on how to apply it. The authors have defined four strategies which cover most of the cases:

1. Dimensioning without a specific agenda - where the recommendations from the standard are used without any specific reason why one dimensioning approach should be favoured over the others. This strategy could be suitable for less important parts or part features; it can often be found in 
engineering drawings made by novice designers. Unfortunately, this strategy is often used by the freshmen students who have not yet successfully adopted the functional or the MTB approach to dimensioning.

2. Dimensioning considering the function or functions of part features - where one chooses the appropriate dimensioning type based on his knowledge/recognition of the importance of the feature in a specific design solution. Since not all part features have equal importance, it is expected to combine this approach with other approaches. This strategy is typical of the senior designers and students at higher years of studies. Freshmen students mostly do not handle functional dimensioning well due to the lack of machine design knowledge.

3. Dimensioning considering the manufacturing steps needed to produce a part with the required features - where one chooses the appropriate dimensioning strategy based on his presumption of the manufacturing method, manufacturing steps, and their order. Although this strategy is applicable to many cases, it is not likely to be used exclusively, especially considering the modern manufacturing technologies.

4. Dimensioning which incorporates functional and manufacturing approaches to dimensioning. This strategy is most likely to be found in properly produced engineering drawings. An experienced designer will emphasise the important dimensions and describe the rest of the part with the MTB dimensions, which could be less important to the function, but very helpful in the manufacturing process.

Considering the number of students with the general secondary education background and the fact that the Engineering Drawing course is taught in the first semester, it seems that only the first strategy is applicable. That, however, is not acceptable because mechanical design by itself calls for accuracy, and dimensioning without a specific plan will most likely result in unwanted problems with the final product. On the other hand, there is no time to teach students about the functions of machine parts and their dimensions or about complex manufacturing technologies. These contents are taught in the second year and later.
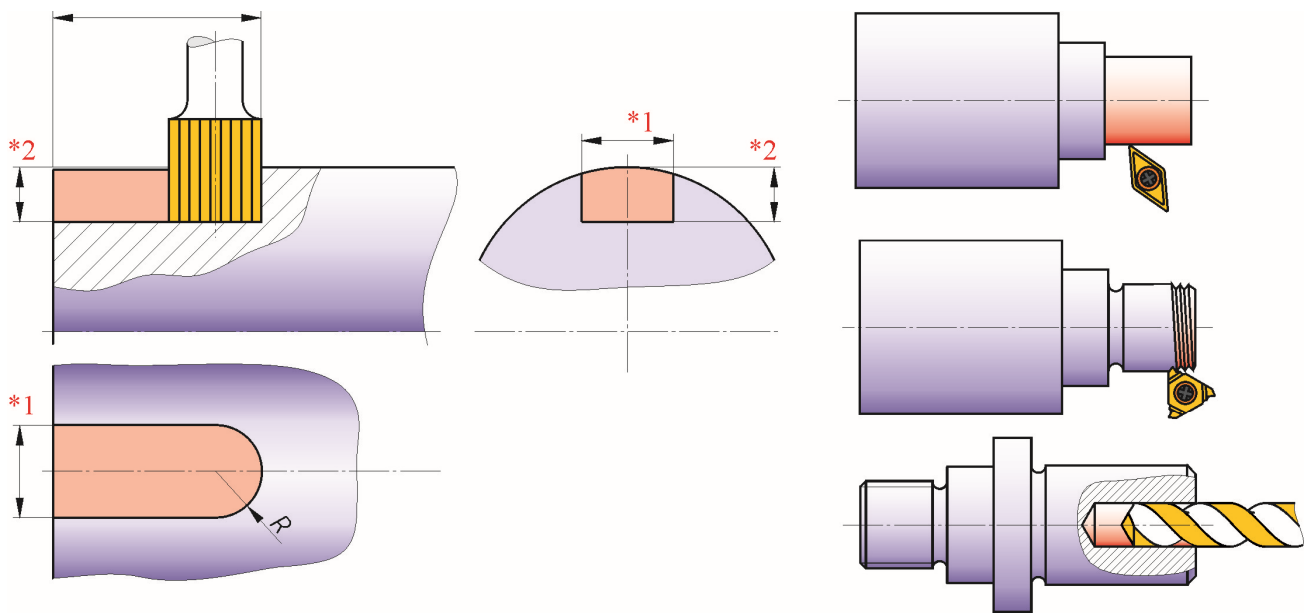

Figure 3. Examples of milling, turning, machine threading, and drilling presentations

Therefore, it was decided that an alternative strategy should be adopted in the teaching of engineering drawing, the one that would be suitable for both the students with the general and the vocational secondary education, and which would present a solid basis for doing the courses in machine parts and mechanical design. The transition from the MTB dimensioning to the functional dimensioning (or the combination of the two) that would be needed later was considered as a feasible and the least harmful solution regarding the goal.

Today, this alternative strategy consists of basics of manufacturing technologies, in particular of material removal processes, such as milling, turning, drilling, and threading (inner and outer threads) (Figure 3).

The teaching of these technologies is limited to a small number of tools, just sufficient for explaining the manufacturing of mid-complex parts (Figure 5). An additional limitation refers to the machinery 
itself - in teaching, we use only the universal machine approach. Universal machines are operated directly by humans, without numerical control. In this approach, students learn, for example, about how machining is done, how the raw material is fixed to the machine, why the step ordering is important, and what the "reference surface" is. To present this approach, various sources available on the Web (Alliance for Innovative Manufacturing, 1995) were used, together with presentations and CAD-created simulations. The strategy overview is shown in Figure 4.

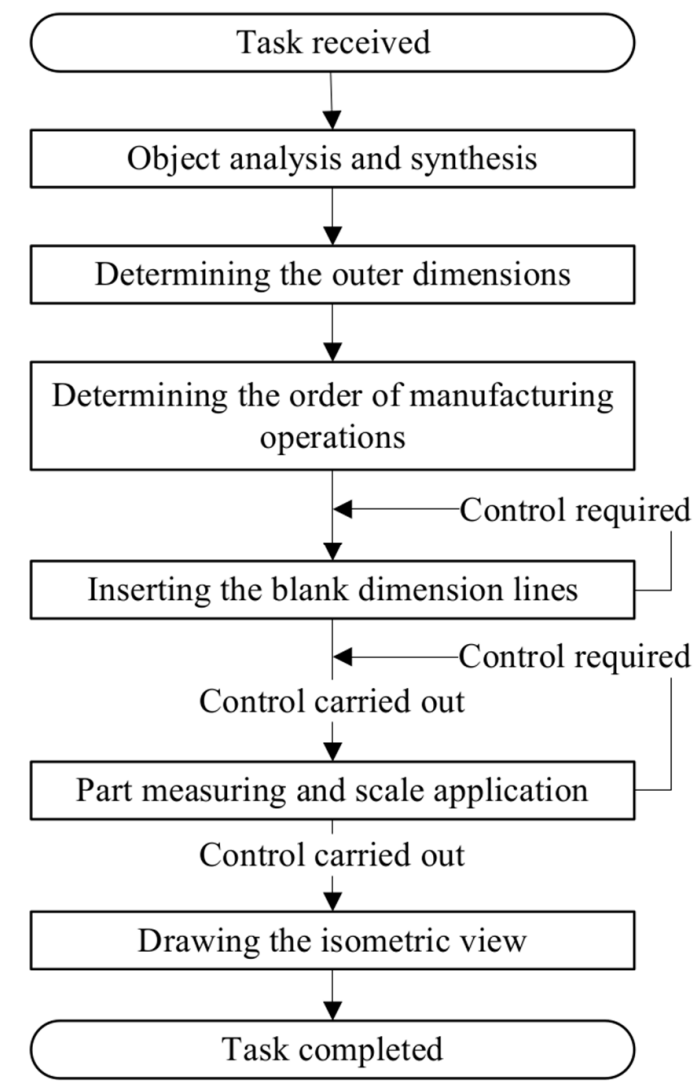

Figure 4. Dimensioning strategy overview

With the strategy defined, it is now possible to get back to the standard (ISO, 2004) and explain the pros and the cons of dimension line arrangements to the students. Furthermore, explanations on how to properly apply them can be given; this can be done taking into consideration the presumption of the manufacturing steps based on the students' limited knowledge of manufacturing technologies and their common sense. We limit the usage of chain dimensioning (based on ISO, 1991) in order to avoid the tolerance error accumulation. Additionally, we provide four simple suggestions, applicable in most of the cases, which can help the students to decide on how to properly arrange the dimensions:

- on the outer side of the part

$\circ$ parallel to the axis, longitudinally, dimensioning the path of the tool

$\circ$ perpendicular to the axis, transversally, dimensioning the measure needed to achieve

0 from the biggest features to the smallest one

- on the inner side of the part

- parallel to the axis, longitudinally, dimensioning the path of the tool

$\circ$ perpendicular to the axis, transversally, dimensioning the measure needed to achieve

○ from the smallest feature to the biggest one

Lastly, the students are warned that this dimensioning approach is not flawless or unquestionable, but that it will serve them as a good reference in the further studies. 


\section{Evaluation method}

Students who have successfully passed the state graduation exam are enrolled and attend the Engineering Drawing course during their first semester. In order to take the final exam, students have to attend the weekly lectures and design exercises. At the end of the semester, the students take the final exam. The task they have to accomplish is to lay down dimensions that would clearly and undoubtedly define the parts in all details. Examples of course exam questions are shown in Figure 5. After the exam, the students were asked to fill in the questionnaire shown in Figure 6. The return of the questionnaire was optional.
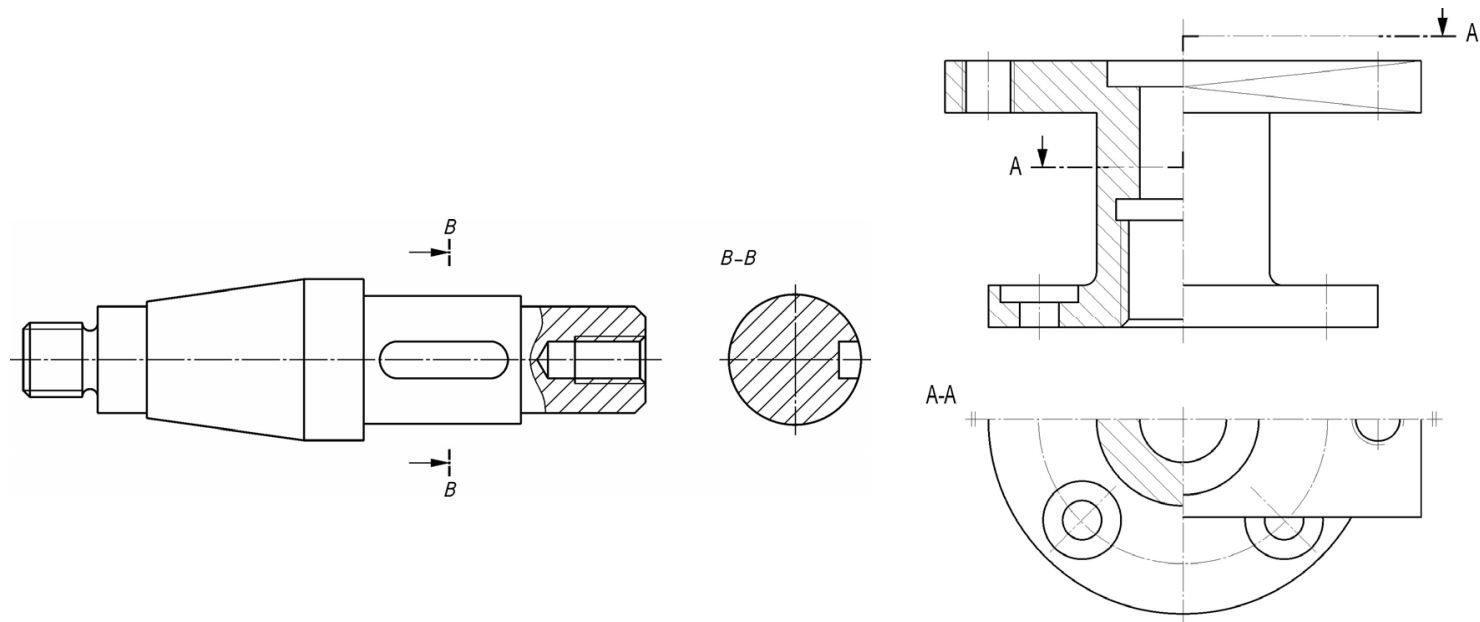

Figure 5. Examples of a final exam task: Shaft and flange

The final exam data were collected at the end of the semester. The academic grading system in Croatia (Ministry of Science, Education and Sports, 2017) consists of grades 1 (insufficient, 0 to 50\%), 2 (sufficient, $51 \%$ to $69 \%$ ), 3 (good, $70 \%$ to $79 \%$ ), 4 (very good, 80 to $89 \%$ ) and excellent ( $90 \%$ to $100 \%$ ). The only failing grade is 1 . In order to get a passing grade, students have to exhibit the knowledge of dimensioning recommendations according to the standard (ISO, 2004), recognize and designate features (diameters, threads, cones) and apply the MTB approach in arranging dimensions.

\section{How would you rate the shaft machining video shown during the lecture?
$\square$ didn't see it
$\square$ too fast
$\square$ not clear
$\square \operatorname{good}$
outstanding

2. How would you best describe the shaft machining shown in the lecture notes?

$\square$ haven't seen it $\square$ too detailed $\square$ clear $\quad \square$ unnecessary

3. Solving the exam examples was:

$\square$ haven't done it $\square$ too detailed $\square$ not clear $\quad \square$ unnecessary $\square$ useful

4. Have the videos showing machining technologies been helpful?
$\square$ haven't seen them
$\square$ had already known that
$\square$ no
$\square$ yes

5. Which materials have you used while studying for the exam (multiple answers possible)?

$\square$ haven't prepared $\square$ lecture notes $\square$ book $\square$ wEB other

6. Did you have a course similar to Engineering Drawing during your secondary education?

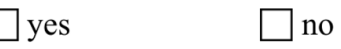

If the answer to question 6 is yes, answer the following:

7a. Were the lecture approaches to dimensioning similar? $\square$ yes $\square$ no

7b. If not, which one have you found more suitable? $\square$ secondary education $\square$ Engineering Drawing

Figure 6. Student exit questionnaire 
At the end of the semester, students were asked to fill in the questionnaire consisting of 8 questions (Figure 6). The first four questions were focused on the students' understanding of the manufacturing processes and the MTB approach to engineering drawing. The sixth question allowed us to differentiate the students who finished vocational secondary education (group A) from those who finished the general secondary education (group B); this is important because the latter had no prior experience with engineering drawing. The last two questions allowed the students who attended vocational secondary schools to compare the teaching approaches.

\section{Results and discussion}

The final grades and the student feedback were collected during a 5 year period, between 2012 and 2017, during which a total of 2197 students attended the Engineering Drawing course. There were 497 group A and 1700 group B students. The remaining 83 students were not considered due to the lack of similarity with either vocational or general secondary schools. During the same time period, 814 exit questionnaires $(37.1 \%$ of the students) containing the student feedback were collected. Thus, the effectiveness of teaching engineering drawing by using the MTB approach was analysed using two sets of data.

In total, 48 students $(2.18 \%)$ were graded as insufficient and had to retake the course. Out of the students that had passing grades, $18.3 \%$ (402 students) were graded as sufficient, $26.76 \%$ (588 students) as good, $27.99 \%$ (615 students) as very good, and 24.76\% (544 students) as excellent (Figure 7). When compared to the year 2011, when the additional learning materials were not available, grades in the period 20122017 are on average higher. In 2011, out of 420 students, $3.03 \%$ of students were graded as insufficient, $9.76 \%$ as sufficient, $31.19 \%$ as good, $38.57 \%$ as very good, and $17.38 \%$ as excellent. The number of students with the grade "excellent" rose by $7.38 \%$ while the number of "very good" students fell by $10.57 \%$, which means that it was easier to obtain the highest grade. At the same time, the number of students achieving the grade "sufficient" rose by $8.57 \%$, mostly due to the increase in the number of students enrolled, which rose from 420 to an average of 480 students during the 2012-2017 time period. The increase in quotas resulted in less demanding requirements for enrolment, which in turn resulted in a lower level of the student prior knowledge.

A normal distribution of grades, i.e. the Gaussian distribution, states that $15 \%$ of the students who have displayed the satisfactory level of knowledge should be graded with sufficient and excellent grades, respectively, and 35\% with good and very good, respectively. By observing the grade distribution, one can conclude that the majority of students have no problems with the engineering drawing, even though the results in the courses taken after the Engineering Drawing course deny this fact.

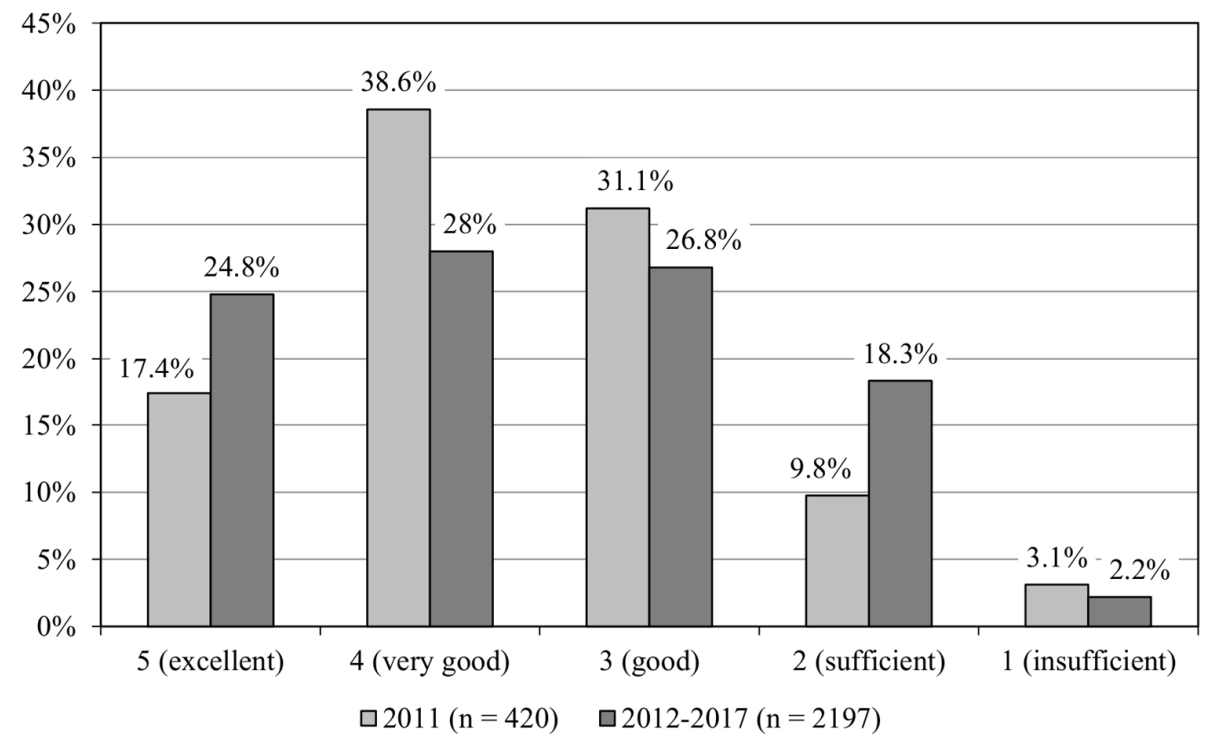

Figure 7. Grade distribution 
Additionally, 814 student exit questionnaires were analysed. Answers to the questions regarding the clarity of the manufacturing process which was shown in the lecture (Figure 8) imply that the largest part of the students understood the basics. The shaft machining video was rated as good or outstanding by $617(75.8 \%)$ students, while $142(17.44 \%)$ found the video too fast and hard to understand. Fifty-five students $(6.77 \%)$ did not attend the lecture in which the video was shown. Alongside the video, a stepby-step shaft machining process was shown in the lecture notes. The notes were described as clear by $702(86.24 \%)$ students, while 61 students $(7.49 \%)$ found them too detailed or unnecessary. Fifty-one $(6.27 \%)$ students did not see the notes. The final exam examples were shown and solved during the lecture. They were found useful by 605 students $(74.32 \%)$, while 24 students $(2.95 \%)$ described them as too detailed or unnecessary. Forty-six students (5.65\%) did not understand them, while $139(17.08 \%)$ did not attend the lecture. Lastly, videos showing various machining technologies were shown to better illustrate the process. They were helpful to 598 students (73.46\%), while 161 students (19.78\%) felt that there was no benefit.

How would you rate the shaft machining video shown during the lecture?

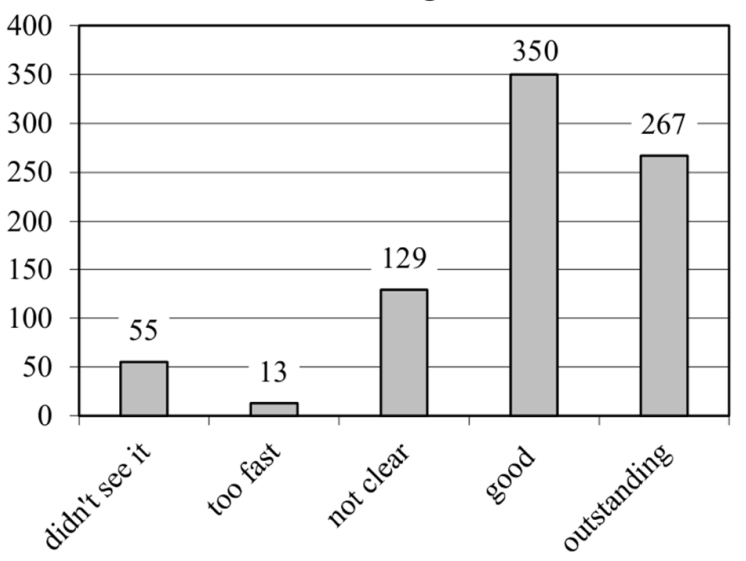

Solving the exam examples was:

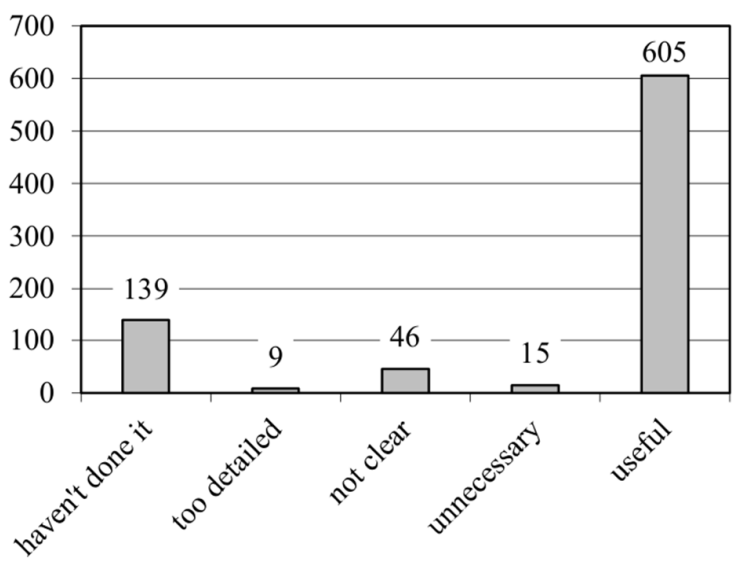

How would you best describe the shaft machining shown in the lecture notes?

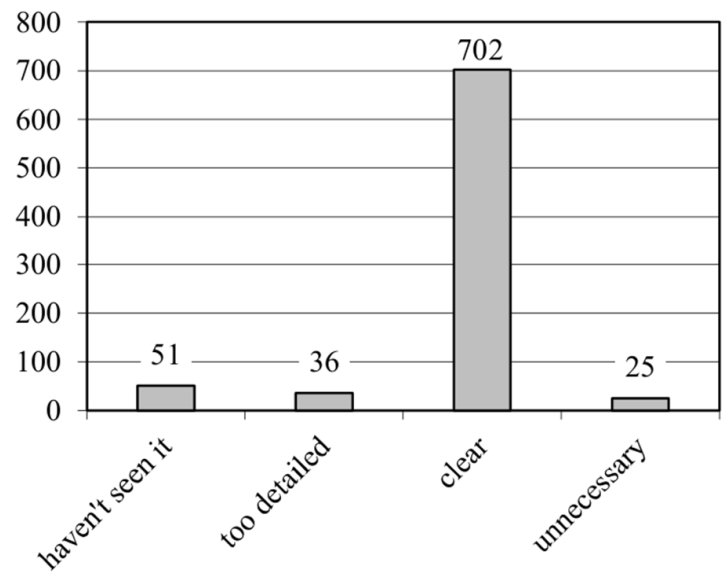

Have the videos showing machining technologies been helpful?

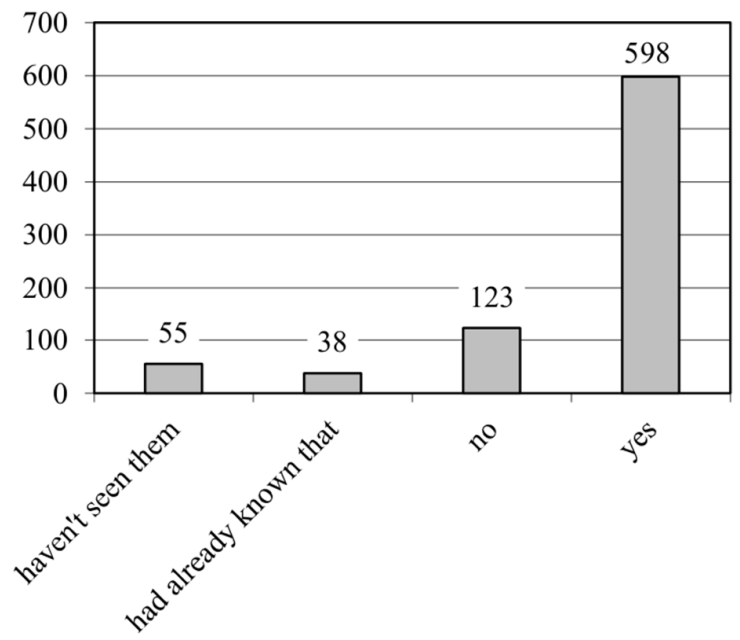

Figure 8. Answers to questions 1-4

The results of the student questionnaires have shown that three quarters of the students understood the basics of manufacturing processes and dimensioning using the MTB approach. By comparing the 
students' feedback with the final grades, one can note that a similar percentage of the students $(79.6 \%)$ achieved grades 3 (good) and higher. The number of students who did not attend the lectures or understand the lecture materials coincides with the number of the lowest grades.

Most of the students found the lecture notes to be most useful; the authors speculate that the step-bystep approach was more successful than the video since it gives students more time to understand the process. Furthermore, lecture notes, while lacking the fluidity presented in the video, show the dimensions added after each phase of the manufacturing process.

Of 814 students who filled in and returned the questionnaire, 184 attended vocational schools and thus had prior education in technical drawing (Figure 9). Teaching approaches were similar for 103 students $(56 \%)$. For the remaining students, the teaching approaches to dimensioning taught in secondary schools were different from the approach presented in the Engineering Drawing course. Fifty-eight students (71.6\%) preferred the engineering drawing approach.

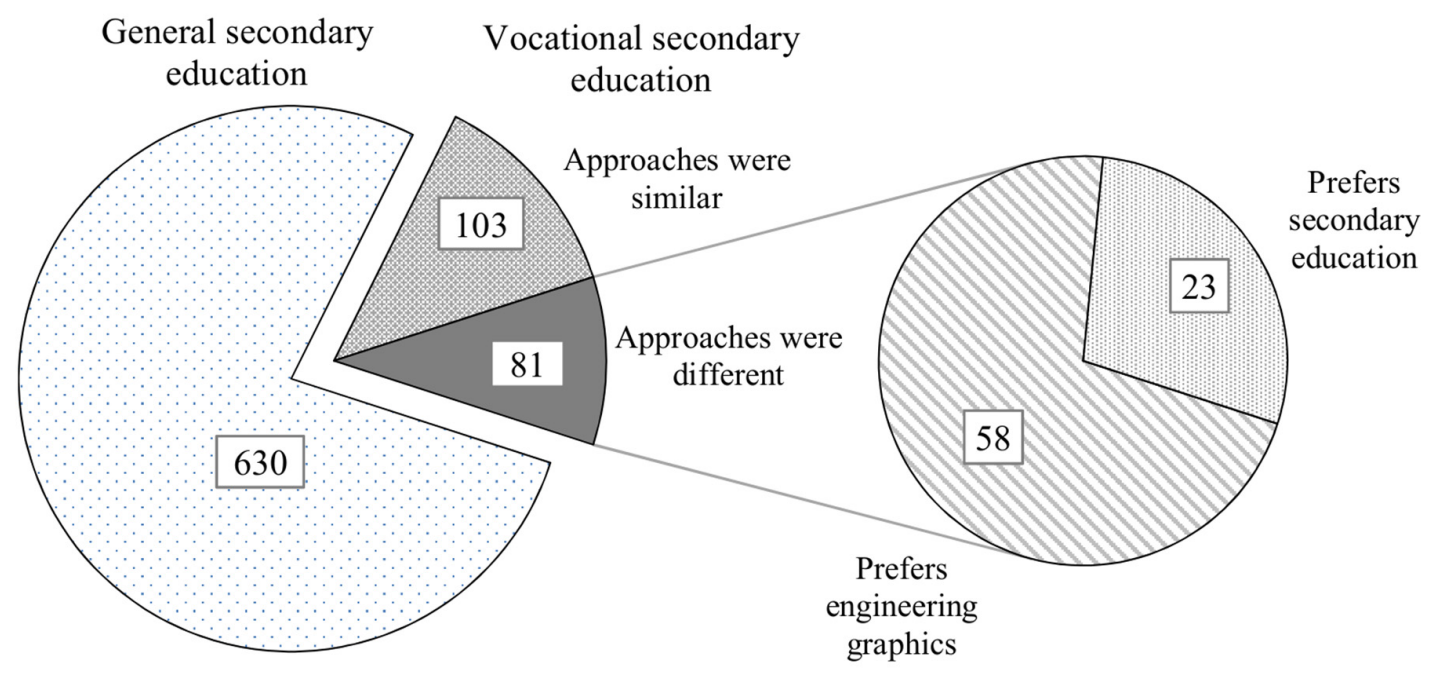

Figure 9. Prior secondary education and dimensioning approach preferences

\section{Conclusion}

The study was conducted to gain a deeper insight into the problems that freshmen students encounter when taking the Engineering Drawing course. In order to help the students to master the course, a number of additional learning materials consisting of lecturing notes and manufacturing process videos were created. In the period 2012-2017, 2197 freshmen took the course and completed it with a $97.82 \%$ success rate. Besides the final grades, 814 student questionnaires returned on a voluntary basis were analysed. The students had different secondary education backgrounds; those who attended vocational schools had a basic knowledge of manufacturing processes and engineering drawing. On the other hand, the students with general secondary education had no such knowledge.

Most of the students found the additional learning materials helpful. Lecture notes were preferred when compared to videos describing manufacturing and dimensioning processes. Furthermore, the students who attended vocational secondary schools stated that the teaching approaches in vocational schools and at FMENA were similar. Of those who found the teaching approaches different, $71.6 \%$ preferred the MTB approach taught during the Engineering Drawing course. A better understanding of manufacturing processes would surely enable the students to grasp the MTB approach to engineering drawing faster. The authors speculate that teaching the basic manufacturing courses before or simultaneously with the Engineering Drawing course would further improve the results.

For a future work, a psychometric analysis of spatial perception for all the students attending the course is planned. Also, by including the results of Design Elements course taught during the second year would enable continuous monitoring of the student development. 


\section{References}

Alias, M., Black, B.R. and Gray, D.E. (2002), "Effect of instruction on spatial visualization ability in civil engineering students", International Education Journal, Vol. 3 No. 1, pp. 1-12.

Alliance for Innovative Manufacturing (1995), How Everyday Things Are Made. [online] Think Media Inc. Available at: http://manufacturing.stanford.edu/hetm.html (accessed 29.11.2017).

Baronio, G., Motyl, B. and Paderno, D. (2016), “Technical Drawing Learning Tool-Level 2: An Interactive SelfLearning Tool for Teaching Manufacturing Dimensioning”, Computer Applications in Engineering Education, Vol. 24 No. 4, pp. 519-528. https://doi.org/10.1002/cae.21728

Eurostat (2017a), Population by educational attainment level, sex and age (\%). [online] Eurostat. Available at: http://ec.europa.eu/eurostat/data/database (accessed: 21 December 2017).

Eurostat (2017b), Population aged 15-34 by educational attainment level, sex, age and programme orientation (\%). [online] Eurostat. Available at: http://ec.europa.eu/eurostat/data/database (accessed: 21 December 2017).

Hampf, F. and Woessmann, L. (2016), "Vocational vs. General Education and Employment over the Life-Cycle: New Evidence from PIAAC”, CVER Discussion Paper Series, CESifo Working Paper, Vol. 63 No. 3, pp. 255269. https://doi.org/10.1093/cesifo/ifx012

ISO (2004), ISO 129-1:2004 Technical drawings -- Indication of dimensions and tolerances -- Part 1: General principles, International Organization for Standardization, Geneva, Switzerland.

ISO (1991), DIN ISO 2768-1:1989 (edition 1991) General tolerances - Part 1: Tolerances for linear and angular dimensions without individual tolerance indications, International Organization for Standardisation, Geneva, Switzerland.

Ministry of Science, Education and Sports (2017), Primary and Secondary School Education Act, Zagreb, Croatia.

Robb, D.A., Childs, P.R.N. and Flora, H. (2009), "Sketching to Solid Modelling Skills for Mechanical Engineers", International Conference on Engineering and Product Design Education 10 \& 11 September 2009, University of Brighton, UK.

Ullman, D.G., Wood, S. and Craig, D. (1990), "The Importance of Drawing in the Mechanical Design Process", Computer \& Graphics, Vol. 14 No. 21, pp. 263-274. https://doi.org/10.1016/0097-8493(90)90037-X

Dragan Žeželj, Associate Professor

University of Zagreb, Department of Design

I. Lucica 5, 10000 Zagreb, Croatia

Email: dragan.zezelj@fsb.hr 